\title{
A CONTRIBUiÇÃo DO TEXTO DE DIVULGAÇÃo CIENTÍFICA NO PROCESSO DE ENSINO E APRENDIZAGEM DOS CICLOS BIOGEOQUÍMICOS
}

\author{
THE CONTRIBUTION OF THE TEXT OF SCIENTIFIC DISSEMINATION IN THE \\ TEACHING AND LEARNING PROCESS OF BIOGEOCHEMICAL CYCLES
}

DOI: 10.23926/RPD.2526-2149.2020.v5.n2.p922-943.id681

\section{Wagner Moisés Costa \\ Mestre em Ensino de \\ Ciências (IFSP) \\ Professor da rede estadual de ensino de São Paulo. \\ wgrcosta@hotmail.com}

\section{Andre Perticarrari \\ Doutor em Ciências (USP) \\ Professor do Instituto \\ Federal de São Paulo (IFSP) \\ aperticarrari@ifsp.edu.br}

Resumo: Os materiais instrucionais mais utilizados nas escolas são os livros didáticos (LD). Entretanto, observa-se um uso frequente de textos de divulgação científica (TDC). O trabalho analisou como o uso de um TDC, vinculado ou não ao uso do LD, auxiliou a mediação entre professor e alunos do Ensino Médio. Os dados foram coletados através de observações de três oficinas por meio de filmagens e analisados utilizando-se a teoria de "Conversas de Aprendizagem" baseada em conversas estabelecidas por frequentadores em museus em uma perspectiva sócio cultural e adaptada para o ambiente formal. Constatou-se que a utilização de TDC articulada ao LD permitiu ao professor mediar o processo ensino/aprendizagem de forma mais enriquecedora, motivando os alunos a uma maior participação nas atividades, evidenciado pela maior frequência de conversas em diferentes categorias, e contribuindo para que a aprendizagem fosse realmente significativa.

Palavras-chave: Divulgação científica. Mediação. Ensino de ciências.

\begin{abstract}
The didactical materials most used in science teaching are textbooks. However, the use of popular science texts is increasing in schools. The aim of the study was to analyze how the use of a popular science text contributed to mediation between teachers and high school students. Data were collected through observations of different interventions recorded in video: use of Textbook, use of Popular Science Text and Textbook and Popular Science Text used together. The data were analyzed qualitatively based on the theoretical framework of Vygotsky and the "Learning Conversations". The results of this study suggest that the use of Popular Science Text associated to the Textbook allowed to the teacher to mediate the process of teaching and learning in a more enriching way, motivating the students to a greater participation in the activities, evidenced by the greater frequency of conversations in different categories.
\end{abstract}

Keywords: Science teaching. Mediation. Popular Science. 


\section{INTRODUÇÃO}

No Brasil, dentre os materiais instrucionais mais utilizados nas escolas, principalmente na promoção do ensino e aprendizagem nas áreas das ciências, estão os livros didáticos (LD) utilizados como referência de pesquisa, devido à facilidade de acesso para professores e alunos como meio de obtenção de informações (SILVEIRA; ARAUJO, 2014).

Observa-se um uso cada vez mais frequente de textos de divulgação científica (TDC) em ambiente escolar (ROCHA, 2012) e também a inserção desse tipo material em LD (MICELI; ROCHA, 2019). Esses materiais são elaborados com a finalidade de divulgar pesquisas e estudos correlacionados ao dinamismo do meio cientifico na atualidade. Desta forma, podem tornar acessíveis os conhecimentos produzidos no meio acadêmico ao público em geral, apresentando uma linguagem de menor complexidade e mais próxima do cotidiano das pessoas (COLAÇO et al., 2007; ROSA; GOI, 2020).

De forma geral, o TDC permite uma atualização de conhecimentos científicos, enquanto no LD isso acontece mais lentamente. Com isso, devido à velocidade da produção científica nos dias de hoje, o conhecimento veiculado no LD não acompanha esse progresso e segue um ensino mais tradicional com a finalidade de atender objetivos de um programa estabelecido por documentos curriculares. Assim, apresenta outros objetivos diferentes dos TDC, que é a de divulgar a produção científica atual e seus debates ao grande público.

Alguns estudos demonstraram a necessidade de permanente atualização dos conteúdos e a maneira na qual são ensinados. Autores como Loiola, Zancul e Bizerril (2013), Martins, Nascimento e Abreu (2004), Chaves e Machado (2005), Rocha (2010; 2012) e Cachapuz et al. (2005) concordam ao destacar a importância da utilização de outros recursos metodológicos para melhorar a forma como se ensina conceitos científicos e seu entendimento por parte dos alunos.

Diante do momento no qual encontra-se o ensino de ciências, o processo de aprendizagem leva em consideração a construção do conhecimento a partir dos conceitos prévios dos alunos, adquiridos por meio de experiências em outros ambientes e sua transformação conceitual para mais próximos dos conceitos científicos e a contextualização dos mesmos (CACHAPUZ et al., 2005). Podemos considerar, então, a articulação entre TDC e LD para subsidiar a mediação do professor nesse processo de construção do conhecimento. Portanto, diante do dinamismo da sociedade e constante produção de estudos e pesquisas nos mais diversos segmentos científicos, a divulgação dos resultados pode promover a atualização das informações. Sendo assim, o uso de TDC poderia complementar o LD, o qual vem sendo 
exclusivamente utilizado como único recurso para promover a aprendizagem em sala de aula, sendo que seus conteúdos muitas vezes estão distantes do cotidiano ou situações vivenciadas pelos estudantes. O TDC pode ser uma ferramenta importante na contextualização dos fenômenos trabalhados na escola.

Desta forma, trabalho teve como objetivo analisar como o uso de um Texto de Divulgação Científica (TDC), vinculado ou não ao uso do Livro didático (LD), auxilia a mediação entre professor e alunos do Ensino médio de uma escola pública estadual na compreensão sobre ciclos biogeoquímicos.

\section{Pressupostos teóricos}

O pensamento científico relacionado com as mais variadas necessidades sociais implica em um ensino transformador. Compreender os processos de produção e de desenvolvimento tecnológico se torna um fator relevante nos dias atuais.

Como bem nos assegura Delizoicov, Angotti e Pernambuco (2009), pode-se dizer que o ensino de ciências pode potencializar a divulgação dos avanços da ciência para a população. Neste contexto, a divulgação pode ser a grande integradora entre a sociedade e a produção científica. O mais importante, contudo, é constatar que o professor necessita centralizar seus esforços para que os estudantes possam se apropriar de tais conhecimentos. Entretanto, as informações podem estar desatualizadas nas escolas, pois os livros didáticos não acompanham o progresso das Ciências e prioriza conceitos abstratos e distantes da realidade dos jovens. Desta forma, a divulgação científica pode contribuir para a integração entre o que está sendo produzido pela ciência com a sala de aula e, com isso, o professor pode se apropriar desses conhecimentos e fomentar situações que propicie ao aluno integrar-se ao que está sendo discutido atualmente na sociedade.

Mesmo que a divulgação seja distante do cotidiano da escola, ela tem um papel importante na atualização do conteúdo, pois pode contemplar temas incluídos nos currículos oficiais escolares, embasando discussões sobre temas atuais e novas áreas do conhecimento (BESSA; FRANÇA; ARNT, 2015). Os autores deixam claro, assim, que a divulgação científica pode atualizar e contextualizar conteúdos trabalhados em sala de aula. Conforme citado acima, para a promoção disto, seria interessante a inserção de TDC nas aulas para fomentar a discussão de temas científicos atuais.

Em revisão da literatura sobre pesquisas realizadas com o intuito de verificar a relevância do emprego do TDC como recurso didático no ensino de ciências, realizado por 
Ferreira e Queiroz (2012), verifica-se uma grande variedade de estratégias no emprego deste material e dos objetivos estabelecidos para seu uso, tais como, fomentar hábitos de leitura e a participação dos alunos nos debates promovidos em sala de aula; favorecer a compreensão sobre aspectos da produção do conhecimento científico, o que faz aproximar, de forma atitudinal e procedimental, os conceitos formulados pelos alunos da linguagem e pensamento científico; promover o interesse e despertar a curiosidade devido à proximidade dos temas com o cotidiano; estimular o pensamento crítico; favorecer a aprendizagem de conceitos e o desenvolvimento de habilidades de comunicação oral e produção escrita.

Fica evidente, diante desse quadro, que o emprego do TDC como recurso didático no ensino de ciências, além de ser um instrumento de divulgação científica, pode contribuir para aquisição de conhecimentos relacionados aos processos de produção científica e tecnológica e potencializar aquisição de habilidades a serem praticadas no cotidiano. Entretanto, o TDC sozinho não daria conta de todas as potencialidades visto acima. Neste processo, a ação do professor se faz necessária, mas não como mero transmissor de temas atualizados, mas de mediador, em que alunos e docente promovam a aproximação do conhecimento escolar social e historicamente construído com os novos conhecimentos ainda não presentes nos LD. Mas, o que se entende por mediação e o papel do professor neste processo?

O termo mediação vem sendo adotado no cenário acadêmico com maior frequência nos últimos anos, principalmente no meio educacional. Dependendo do ambiente no qual seja adotado, pode assumir diversos significados e objetivos, principalmente quando se trata de interação entre pessoas, cabendo a cada envolvido inferir sentido ao termo, quando associado aos objetivos desse meio.

Porém, sendo mais adotado por educadores, parece haver consenso que a mediação se apresenta como parte central do processo educativo (ALMEIDA; ARNONI; OLIVEIRA, 2006). Para estes autores, a mediação pode ser entendida como a estratégia que possibilita articular, encurtar a distância entre ensino e aprendizagem, unindo os conhecimentos originários do cotidiano e daqueles de caráter científico.

A partir da primeira metade do século XX, vários estudos foram elaborados associando o termo mediação à preocupação relacionada às estratégias que são utilizadas para promoção da aprendizagem (VAN DER VIER; VALSINER, 2006). Na segunda metade do referido século, a importância atribuída à mediação por parte da comunidade educacional é reconhecida, sendo considerada como central no processo que permite a aproximação do sujeito ao objeto, que efetua a apreensão e oferece significado ao objeto compartilhado por quem realiza a 
mediação e o grupo de sujeitos menos experientes (REGO, 1994). Neste sentido, os professores deveriam conferir a importância necessária que permita a construção de um aprendizado coletivo, através do planejamento de atividades e situações de aprendizagem que permitiriam ao aluno se apropriar do conhecimento de forma a conferir novos significados e habilidades sócio cognitivas (MARTINS, 1997).

De acordo com Vygotsky (2011), a função primordial do professor é promover situações em que ocorra a mediação. Se respeitado os conceitos espontâneos trazidos pelo aluno e desenvolvidos em situações informais do cotidiano, por meio da mediação, torna-se possível a transformação desses em conceitos científicos através da linguagem em ambientes formais de ensino. O conceito de mediação compreendido por Vygotsky conserva as relações estabelecidas pelo homem com o ambiente no qual está inserido por meio do uso de signos, em especial a linguagem, com base no conhecimento histórico e culturalmente acumulado pela sociedade (FREITAS, 2000).

Para Vygotsky, o ensino de conceitos sempre será realizado por elementos do grupo cultural no qual o sujeito está inserido, ou seja, "os membros imaturos da espécie humana vão pouco a pouco se apropriando dos modos de funcionamento psicológico, do comportamento e da cultura, enfim, do patrimônio da história da humanidade e de seu grupo cultural" (REGO, 1994, p. 61). Neste sentido, "o conhecimento e o aluno são unidos, através da mediação proporcionada pelo professor que fundamenta suas ações definidas pela cultura, que permita aos alunos construir significados" (PILETTI, 2015, p. 98-99).

Assim, o professor assume uma posição de facilitador entre os alunos e o objeto do conhecimento, promovendo "demonstrações, explicações, justificativas, abstrações e questionamentos", enfim, o necessário para a consolidação das estruturas cognitivas do aluno (REGO, 1994, p.115). Em relação ao papel do aluno, vale destacar que, quando manifestado por ele a disposição de interação, participação e envolvimento, contribui para que sejam mobilizadas estratégias internas que permitem melhor interação e formação de sua estrutura cognitiva, tomando para si parte da criatividade do professor (MARTINS, 1997). A aprendizagem surge, então, como unidade integradora do aluno ao conhecimento, transformadora dos conceitos espontâneos a científicos, modificando suas estruturas mentais (La TAILLE; OLIVEIRA; DANTAS, 1992). Também destaca que para haver tais mudanças, se faz necessária a intervenção pedagógica realizada na escola, por meio do professor, ou seja, é imprescindível a interação com outros indivíduos (La TAILLE; OLIVEIRA; DANTAS, 1992). 
Freitas (2009) afirma que os recursos didáticos, por melhor elaborados que sejam, devem garantir aproximação entre professor e aluno, sendo utilizados no processo de mediação do conhecimento e consolidação dos conceitos que formam as estruturas mentais. Assim, "eles cumprem a função de mediação e não podem ser utilizados como se fossem começo, meio e fim de um processo didático [...]" (FREITAS 2009, p. 24). Diante disso, o professor deve atuar de forma que os conceitos provenientes de ambientes informais, ou seja, aquilo que os jovens trazem para sala de aula - conceitos espontâneos - sejam transformados na escola em conceitos organizados.

O processo de desenvolvimento mental, proposto por Vygotsky, postula que o indivíduo mais experiente conduz o menos experiente através da mediação com o objeto, de forma a desenvolver operações mentais mais elevadas, na qual denominou de Zona de Desenvolvimento Proximal (ZDP). Essa mediação permite operações mentais cada vez mais complexas e níveis mais elevados no desenvolvimento intelectual (VYGOTSKY, 2013).

A partir desta perspectiva, o conceito de ZDP começa a ser explorado com mais intensidade, em que se espera que o indivíduo mais experiente, o professor, planeje ações nas quais a mediação ocorra na ZDP (La TAILLE; OLIVEIRA; DANTAS, 1992). Segundo Rego (1994), Vygotsky afirma que a aprendizagem antecede o desenvolvimento psicológico e o ensino ocupa papel central neste processo. Dessa maneira, reforça a ideia de intervenção de pessoas mais experientes no processo de aprendizado do menos experiente, levando o sujeito a consolidar os conceitos previamente adquiridos em outros ambientes.

Para Vygotsky, o ensino interfere na ZDP "estimulando processos internos maturacionais que terminam por se efetivar, passando a constituir a base para novas aprendizagens" (FREITAS, 2000, p. 104), sendo primordial a colaboração entre alunos e professor, permitindo ao estudante "ir além de suas capacidades iniciais" (PILETTI, 2015, p. 94).

Por isso, uma das tarefas do professor é promover ações de modo que a aprendizagem ocorra, o que não ocorre espontaneamente (La TAILLE; OLIVEIRA; DANTAS, 1992). Estas ações são fundamentais, de modo que, através da mediação do docente por meio do diálogo estabelecido, contribua para o estabelecimento dos processos mentais em detrimento daqueles previamente desenvolvidos (REGO, 1994).

Finalmente, de acordo com Loureiro (2004), cabe dizer que o professor é o grande mediador entre o aluno e o conhecimento. Então, podemos considerar que o aprendizado do aluno está relacionado com a cooperação entre os sujeitos com níveis cognitivos mais elevados 
intervindo na ZDP daqueles em processo de amadurecimento (VAN DER VIER; VALSINER, 2006).

Sendo assim, o processo de mediação realizado pelo professor, valendo-se da utilização de instrumentos instrucionais como o LD e o TDC, poderia contribuir com o diálogo entre os sujeitos envolvidos e, assim, promover a formação de estruturas mentais de níveis elevados nos estudantes por meio do processo da formação de conceitos. Como bem nos assegura Vygotsky (2011), este processo é a associação entre o aprendizado recebido na escola - de forma organizada e sistemática - e a maturação cognitiva do indivíduo. De acordo com La Taille, Oliveira e Dantas (1992), cabe à escola descobrir o nível de compreensão do sujeito de determinado conceito espontâneo e, assim, desenvolver o potencial deste sujeito.

\section{MÉtodo}

A presente pesquisa caracterizou-se como qualitativa, já que todo o processo desenvolvido foi levado em consideração. Na pesquisa qualitativa ocorre o contato direto do observador com o fenômeno em estudo, permitindo a obtenção de dados descritivos de um fenômeno e estabelecendo as relações entre as variáveis (GIL, 1999; LÜDKE; ANDRÉ, 2014).

\subsection{UNIVERSO DA PESQUISA E COLETA DE DADOS}

Participaram deste estudo alunos da $1^{\text {a }}$ série do Ensino Médio de uma escola estadual situada no município de Itupeva-SP. Os estudantes foram convidados a participar de oficinas em que foram discutidos temas relacionados aos ciclos biogeoquímicos e suas implicações na saúde e nos ecossistemas, com o apoio do LD e de um TDC. Estas ocorreram no contraturno e os discentes foram distribuídos em 3 grupos. Foram realizadas três intervenções durante as oficinas com diferentes alunos. O primeiro grupo que nomearemos de Intervenção 1-IT1 foi utilizado somente o livro didático. O segundo, IT2, utilizou somente o TDC e o terceiro grupo, IT3, a combinação de LD e TDC. Em todos eles, o professor conduziu a leitura e a articulação de textos para promoção de diálogos com a finalidade de verificar as respostas dos alunos aos questionamentos feitos por ele.

A coleta de dados foi realizada através da observação e da filmagem dos diálogos entre professor-aluno, aluno-aluno com a posterior transcrição das gravações das diferentes oficinas e a categorização das conversas ocorridas entre os sujeitos, utilizando-se o método descrito na próxima seção. 


\subsection{INSTRUMENTO DE ANÁLISE DE DADOS}

A análise e interpretação dos diálogos originados das intervenções (ITs 1, 2 e 3) foram realizadas de acordo com o método de "Conversas de Aprendizagem" desenvolvido por Allen (2002) baseado em conversas estabelecidas em museus por meio da interação entre seus frequentadores em uma perspectiva sócio cultural. Tal metodologia procura categorizar as manifestações humanas capazes de apresentar evidências de aprendizagem nos diálogos existentes tanto em um ambiente não formal quanto em um formal, conferindo sentido às expressões verbais que estão presente em qualquer local onde exista interação social. As categorias utilizadas neste método foram adaptadas para o ambiente formal, sendo as mesmas agrupadas de acordo com a sua aproximação e relação com aspectos relacionados aos conteúdos escolares definidos por Cesar Coll, citado em Carvalho (2012), ou seja, ao conhecimento (conceituais), à afetividade (atitudinais) e aos procedimentos, como mostrado no quadro 1.

Quadro 1 - Categorias de Conversas de Aprendizagem adaptadas de Allen (2002)

\begin{tabular}{|c|c|c|}
\hline $\begin{array}{c}\text { Categorias relacionadas ao } \\
\text { conhecimento }\end{array}$ & $\begin{array}{c}\text { Categorias relacionadas a aspectos } \\
\text { afetivos e de postura }\end{array}$ & $\begin{array}{l}\text { Categorias relacionadas aos } \\
\text { aspectos procedimentais }\end{array}$ \\
\hline $\begin{array}{l}\text { 1- Conversa Conceitual: Interpretações } \\
\text { envolvendo generalizações, articular } \\
\text { conceitos que podem aparecer de forma } \\
\text { simples e complexa, oriundas da } \\
\text { percepção que o aluno pode ter sobre os } \\
\text { elementos contidos nos textos. Apresenta } \\
3 \text { subcategorias: } \\
\text { a) Conceitual simples: inferência de um } \\
\text { conceito. } \\
\text { b) Conceitual complexa: levantamento } \\
\text { de hipóteses, presença de generalizações } \\
\text { de informações ou discussão sobre } \\
\text { relação entre objetos e propriedades. } \\
\text { c) Conceitual de metacognição: } \\
\text { existência de reflexão do aluno sobre os } \\
\text { conhecimentos prévios ou adquiridos } \\
\text { durante as intervenções. }\end{array}$ & $\begin{array}{l}\text { 1- Conversa Estratégica: Conversa que } \\
\text { demonstra a postura dos alunos em } \\
\text { relação as intervenções, provenientes } \\
\text { da discussão sobre o tema proposto } \\
\text { pelo TDC e LD. Inclui } 2 \text { subcategorias: } \\
\text { a) Uso: Levantamento de como os } \\
\text { alunos podem utilizar os conteúdos } \\
\text { trabalhados. } \\
\text { b) Metaperformance: Diálogos que } \\
\text { evidenciam a avaliação feita pelos } \\
\text { próprios alunos sobre seu } \\
\text { envolvimento nas aulas. }\end{array}$ & $\begin{array}{l}\text { 1- Conversa Perceptiva: Evidencia a } \\
\text { atenção dos alunos aos estímulos } \\
\text { presentes no LD e no TDC, como } \\
\text { imagens e gravuras, ou identificando- } \\
\text { os ou caracterizando-os. }\end{array}$ \\
\hline $\begin{array}{l}\text { 2- Conversa conectiva: Demonstra o } \\
\text { vínculo entre o TDC e LD com } \\
\text { experiências ou conhecimentos ligados } \\
\text { ao cotidiano. Reúne } 2 \text { subcategorias: } \\
\text { a) Conectiva com a vida: } \\
\text { Histórias pessoais, possíveis associações } \\
\text { ou comparações de elementos } \\
\text { encontrados nas diferentes intervenções } \\
\text { com o cotidiano. }\end{array}$ & $\begin{array}{l}\text { 2- Conversa Afetiva: O objetivo desta } \\
\text { categoria é verificar nas falas, } \\
\text { expressões que demonstram } \\
\text { sentimentos. Ou seja, atitudes } \\
\text { relacionadas ao conhecimento, ao } \\
\text { professor, às tarefas. }\end{array}$ & $\begin{array}{l}\text { 2- Conectiva Intraexibição: } \\
\text { Conversas que explicitam conexões } \\
\text { entre elementos presentes na } \\
\text { intervenção. Esta subcategoria da } \\
\text { conversa conectiva foi aqui colocada } \\
\text { por entender que está mais } \\
\text { relacionada com conteúdos } \\
\text { procedimentais. }\end{array}$ \\
\hline
\end{tabular}




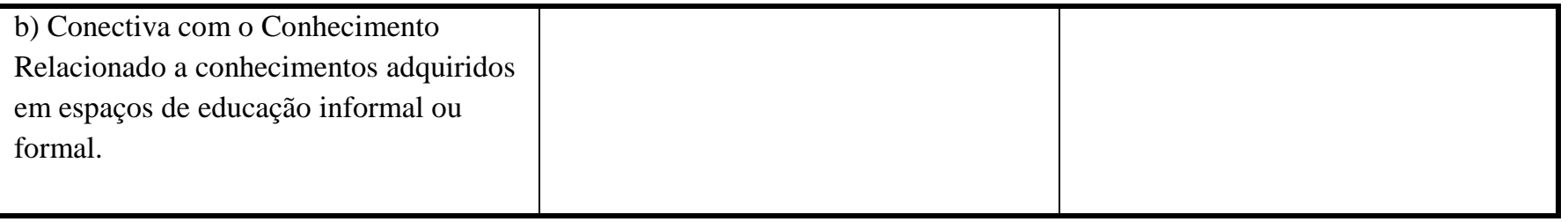

Fonte: os autores

A categorização dos diálogos em conversas de aprendizagem, neste estudo, teve como finalidade revelar possíveis indícios de aprendizagem ocorridos como resultado de interações sociais mediadas pelo professor e as relações estabelecidas nas atividades com o TDC e o LD.

É importante ressaltar a importância da disposição de interação, participação e envolvimento do aluno neste processo, pois isso contribui para que sejam mobilizadas estratégias internas que corroboram com a interação e desenvolvimento de sua estrutura cognitiva, tomando para si parte da criatividade do professor (MARTINS, 1997). Inicialmente eram 23 os alunos participantes, porém, 18 concluíram todas as etapas das intervenções. Vale destacar que os jovens participantes não apresentavam um hábito de leitura constante, apresentando dificuldades na interpretação e nas estratégias de leitura.

A seguir serão apresentados os dados referentes a cada intervenção, que eram realizadas em duas etapas. A primeira, preparação para a leitura e comum a todas elas, era apresentado um vídeo sobre o papel do homem no planeta e sua relação com o meio com objetivo de sensibilizar os estudantes para a próxima etapa. Na segunda, que variou o uso do texto de referência (somente LD-IT1, somente TDC-IT2 e LD+TDC-IT3), os alunos participantes eram divididos em duplas de leitura e contavam com um roteiro com questões norteadoras e posterior discussão. Neste momento, o professor fazia intervenções no intuito de orientar a leitura e estimular a troca de ideias (diálogos) entre os estudantes.

Esta pesquisa foi aprovada pelo Comitê de Ética, parecer número 2.095.987 (CAEE: 68775517.5.0000.5473).

\section{Resultados e Discussão}

\subsection{INTERVENÇÃO 1 - USO DO LD}

Nesta atividade foi utilizado o livro didático "Biologia em contexto - 1 Do Universo as células vivas" dos autores José Mariano Amabis e Gilberto Rodrigues Martho, Editora Moderna $1^{\text {a }}$ edição 2013, Capitulo 4 - Os ciclos da matéria (pp. 72-82) e Capítulo 8 - A humanidade e o ambiente (pp. 152-168). 
De forma geral o LD trata o assunto de forma mais formal, apresentando as definições de ciclo biogeoquímico (presente na página 74) e o padrão de circulação dos elementos químicos. Fundamenta a importância do $\mathrm{CO}_{2}$ para a manutenção dos seres vivos, por formar a estrutura básica de todas as moléculas orgânicas e mostra a relação entre o fluxo de energia dos seres vivos e a regulação da composição atmosférica e o clima, isso na forma de quadro (presente na página 79 do LD). O autor também faz alusão ao uso dos combustíveis fósseis e ação dos seres vivos no aquecimento global e a participação do homem. Os ciclos são apresentados em tópicos e não é mostrada a relação entre eles. Já no capítulo 8, os problemas ambientais são também abordados em tópicos separados e não há relação destes com os desequilíbrios causados nos ciclos biogeoquímicos pela ação humana.

Nesta oficina, verificou-se o maior predomínio de diálogos relacionados ao conhecimento, sendo a Conversa Conceitual Simples a mais frequente (figura 1).

Figura 1 - Frequência, em porcentagem, das categorias de "Conversas de Aprendizagem" que ocorreram na Intervenção 1 (IT1 - somente uso do LD) e tendência linear de sua distribuição nas categorias (linha tracejada)

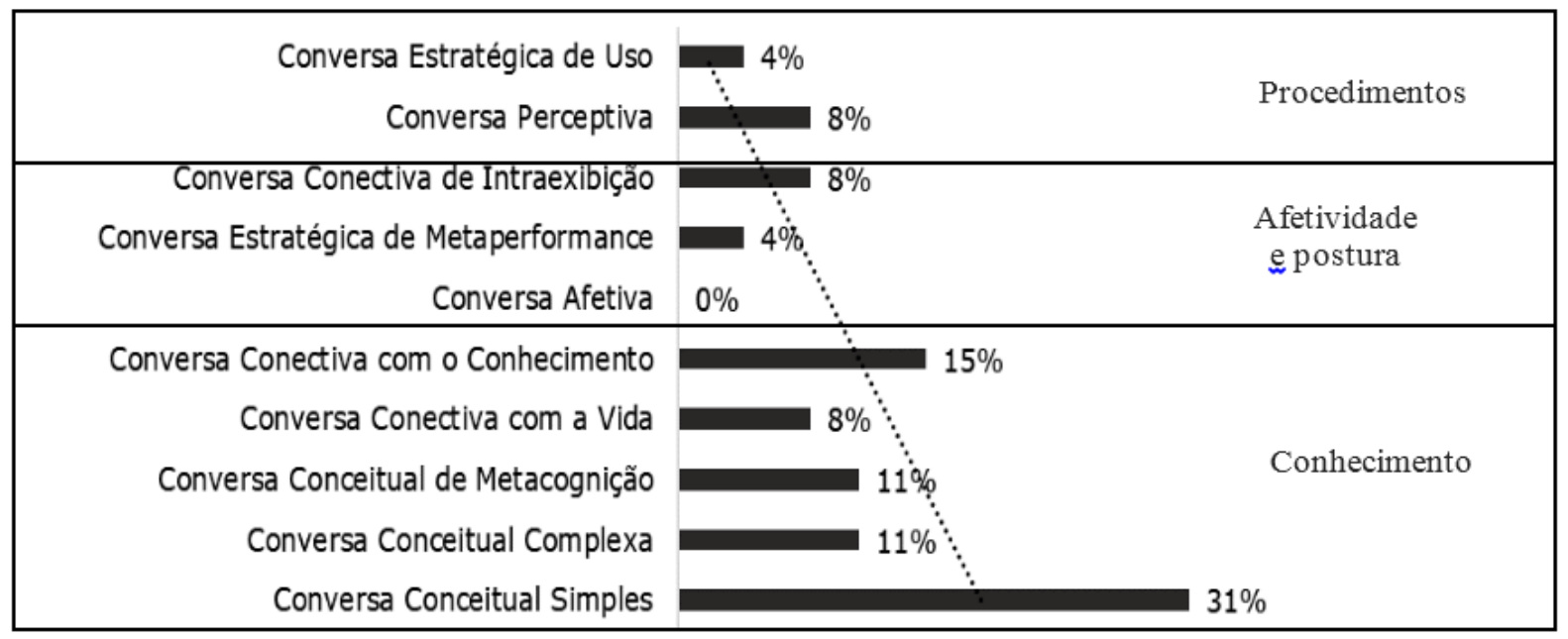

Linear (LD)

Fonte: Os autores

Neste tipo de conversa predomina a conceitualização, ou seja, são feitas declarações simples ou lembranças de termos e fenômenos. Não são realizadas articulações entre as partes, por exemplo, mas somente respondem aos questionamentos feitos pelo professor:

Trecho da oficina

- Professor iniciando o processo de mediação, pergunta: $O$ que aprendemos sobre os ciclos biogeoquímicos? 
- Aluno: Eu entendi que este ciclo acontece porque os elementos orgânicos circulam entre os seres vivos e os não vivos na atmosfera, estão sempre acontecendo e estão presentes.

Mesmo o professor estabelecendo um diálogo com os alunos e estimulando o uso do LD, este tipo de conversa, conceitual simples, continua a aparecer:

Trecho da oficina

- Professor solicita aos alunos refletirem sobre a importância do carbono para vida dos seres vivos, e a partir da leitura do $\mathrm{LD}$, deveriam estabelecer a importância do $\mathrm{CO}_{2}$ na manutenção da vida dos seres vivos.

- Aluno conceitua: O carbono é importante por que está presente na estrutura de todos os organismos!

Percebe-se que não é realizada uma análise mais profunda, mas apenas verbalizando o que estava no livro.

Contudo, observa-se que outras categorias relacionadas ao conhecimento também ocorreram, porém em frequência mais baixa, como é o caso da Conceitual Complexa:

$\underline{\text { Trecho da oficina }}$

- Aluno apresentando conhecimento em transformação sobre o assunto diz: Seja os organismos em estruturas não vivas.

- O professor, identificando uma possibilidade de atuar na ZDP do aluno e promover a cooperação entre eles, imputa: Explique melhor sua afirmação.

- Aluno formula uma possível resposta que apresenta como característica o levantamento de hipótese: Se o carbono faz parte da estrutura de todos organismos, quer dizer que como nada vive eternamente, pode ser encontrado também em estruturas de seres que já morreram e em outras estruturas como as rochas e petróleo. Isso explica porque tem $\mathrm{CO}_{2}$ na fumaça que os carros soltam. Vale lembrar que demonstrou relação entre elementos de características distintas como as rochas e petróleo.

Neste momento foi importante o papel do professor, estimulando o estudante a fazer uma reflexão mais profunda.

De forma geral, os alunos formularam diálogos mais simples com a inferência de um conceito (conceitual simples), com tendência a níveis cognitivos mais baixos. Contudo, com o 
auxílio de recursos visuais presentes no texto, e o direcionamento dos diálogos pelo professor, outras categorias de conversas ocorreram, como a Conectiva de intraexibição, a Perceptiva:

\section{Trecho da oficina}

- Aluno: A relação éo ciclo do nitrogênio. (Conceitual simples)

- Professor: Como você chegou a esta conclusão?

- Aluno formula uma resposta: Aqui no livro fala isso. (Conversa perceptiva).

Nota-se, portanto, maior concentração das categorias de conversas em níveis cognitivos mais baixos e relacionadas ao conhecimento, que exigem pouca articulação entre os conceitos e fenômenos abordados, principalmente a conceitual simples, indicado pela tendência linear observada na Figura 1.

\subsection{INTERVENÇÃO 2 - USO SOMENTE DO TDC}

O TDC utilizado nesta intervenção, "Mudança climática global e o Brasil" de autoria de Simon Torok (2007), abordou a temática do aquecimento global e o papel do homem nesse fenômeno, remetendo ao ambiente e aos efeitos do aquecimento do planeta pela ação humana nos ciclos biogeoquímicos.

Da mesma forma que na intervenção anterior, a categoria que apareceu com mais frequência foi a Conceitual simples, correspondendo a $28 \%$ das falas (Figura 2). 
Figura 2 - Frequência, em porcentagem, das categorias de "Conversas de Aprendizagem" desenvolvidas pelos estudantes na Intervenção 2 (IT2 - somente uso do TDC) e tendência linear de sua distribuição nas categorias (linha tracejada)

\begin{tabular}{|c|c|}
\hline $\begin{array}{l}\text { Conversa Estratégica de Uso } \\
\text { Conversa Perceptiva }\end{array}$ & Procedimentos \\
\hline $\begin{array}{r}\text { Conversa Conectiva de Intraexibição } \\
\text { Conversa Estratégica de Metaperformance } \\
\text { Conversa Afetiva }\end{array}$ & $\begin{array}{c}\text { Afetividade } \\
\text { e postura }\end{array}$ \\
\hline $\begin{array}{r}\text { Conversa Conectiva com o Conhecimento } \\
\text { Conversa Conectiva com a Vida } \\
\text { Conversa Conceitual de Metacognição } \\
\text { Conversa Conceitual Complexa } \\
\text { Conversa Conceitual Simples }\end{array}$ & Conhecimento \\
\hline
\end{tabular}

\section{Linear (TDC)}

Fonte: Os autores.

Em relação à intervenção anterior, nesta percebe-se um pequeno aumento nas categorias Conceitual de metacognição e Conceitual complexa:

Trecho da oficina

- Aluno: No texto também diz isso, porém fala que se reduzíssemos a quantidade de CO2 que havia na década de 90 ainda sofreríamos com seus efeitos. (Conceitual de metacognição).

- Aluno: O efeito estufa acontece porque os gases lançados na atmosfera são aquecidos pelos raios solares que são refletidos no solo. (Conceitual complexa).

Entretanto, observa-se um pequeno aumento nas categorias mais relacionadas à afetividade e postura ativa na busca de informações presentes no texto.

$\underline{\text { Trecho da oficina }}$

- Quando o professor pede que os alunos relacionem as implicações da poluição para os seres humanos, um deles responde:

- Aluno: Podemos ser muito prejudicados, através de doenças, falta de comida, morte por causa do calor. (Conectiva intraexibição).

-Aluno: Podemos morrer de asfixia, altera os batimentos cardíacos! (Conversa afetiva) 
- Aluno: Professor, onde encontro a definição? Observou-se frustração por parte do aluno pelo fato de não ter encontrado (Conversa afetiva).

Da mesma forma que ocorreu com o uso do LD, somente o uso do TDC não levou a uma presença mais frequente de diálogos em outros níveis cognitivos, indicado pela tendência linear presente na figura 2. Entretanto, ainda que pequeno, houve aumento em outras categorias, como àquelas relacionadas à postura e afetividade, talvez devido à característica do texto que aborda a interferência humana no ciclo do carbono e sua relação com o meio ambiente.

\subsection{INTERVENÇÃO 3 - USO DO LD ARTICULADO COM O TDC}

Nesta intervenção o professor usou os mesmos capítulos da intervenção 1, mas agora articulado com o TDC da intervenção 2. Observou-se um aumento das categorias relacionadas à afetividade e postura, assim como a procedimentos (Figura 3).

Figura 3 - Frequência, em porcentagem, das categorias de "Conversas de Aprendizagem" desenvolvidas pelos estudantes na Intervenção 3 (IT3 - uso do LD associado ao TDC) e tendência linear de sua distribuição nas categorias (linha tracejada)

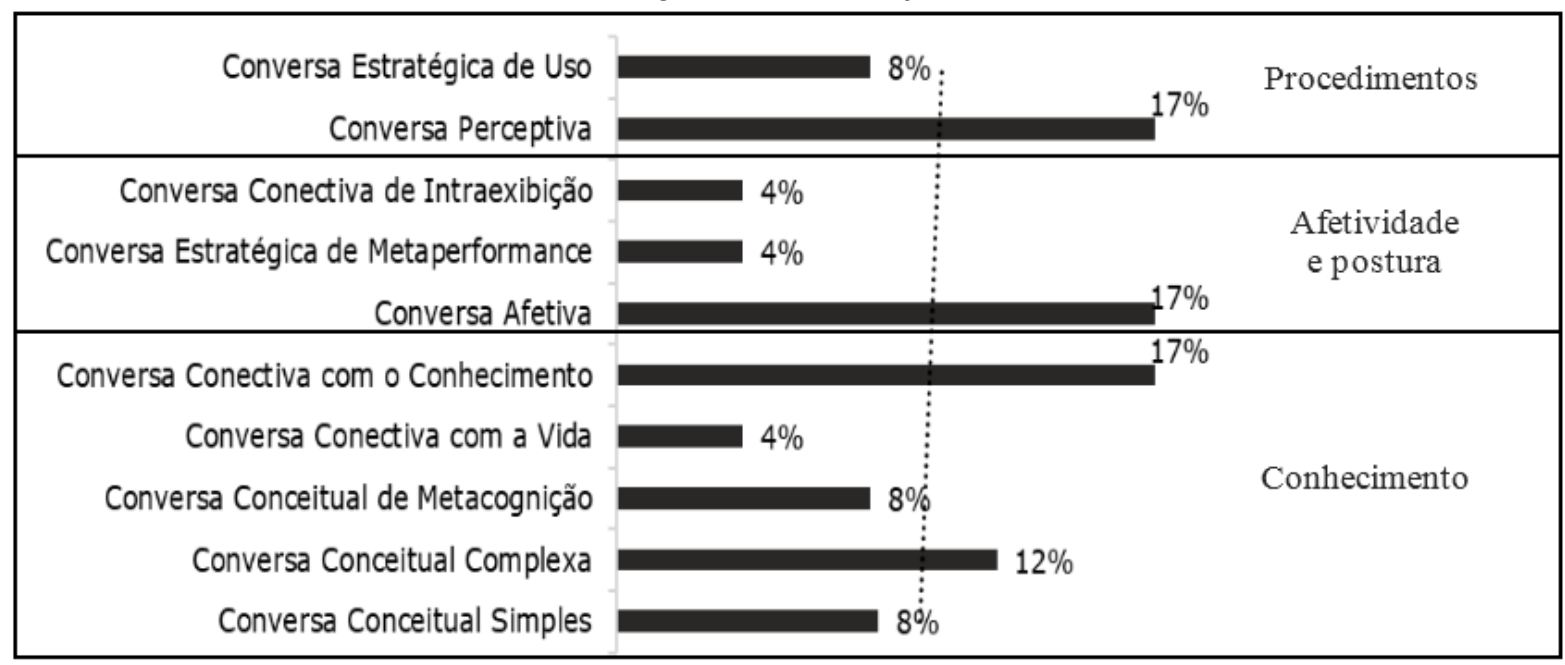

Linear $(T D C+L D)$

Fonte: os autores

Nota-se aqui uma tendência maior (ver tendência linear na figura 3) ao equilíbrio entre as diferentes categorias. Isso pode ser verificado nos diálogos estabelecidos entre os sujeitos e apresentados abaixo.

\section{Trecho da oficina}

- Professor pede aos estudantes que relacionem a queima de combustíveis fósseis com o aquecimento global. 
- Aluno: Contribuem por que são queimados. Tomam a forma de fumaça. A fumaça é tóxica! (Conectiva afetiva).

- Aluno: No Livro diz que os raios solares esquentam a atmosfera e os gases só fazem aumentar a temperatura. (Estratégica metaperformance).

- Aluno: No Texto aqui na página 2 que o homem depende de combustível fóssil para fazer funcionar os motores na indústria. Professor, se aqui está dizendo que o processo é natural, então sempre teve este problema, mesmo quando o homem ainda não tinha desenvolvido as máquinas? (Conversa perceptiva.)

- Professor: O processo do aquecimento global é natural, assim como o efeito estufa. O problema é que quando o processo é natural os seres vivos se adaptam as modificações do ambiente relacionadas ao fenômeno. A questão é que o problema está sendo acelerado, promovendo um grande desequilíbrio ambiental.

- Aluno: É verdade, tanto no livro quanto no texto fala sobre isso. Se o processo é lento os seres vivos tem condições de se adaptar. Agora se não provoca sérios problemas de para a natureza e para os seres vivos. Corremos o risco de ficar sem comida e morrer de calor. (Estratégica de uso).

- Aluno: Aqui no texto tem uma foto de uma fábrica soltando fumaça preta. Fumaça preta é resíduos tóxicos e pesados. No livro também tem imagens de carros soltando fumaça. Qual é a diferença entre os tipos de fumaça? (Conversa perceptiva). Mantida fala original sem correção gramatical (grifo nosso).

- Professor: Aparentemente a diferença se dá no combustível que está sendo utilizado, ocasionando sua toxidade.

E as discussões continuam:

$\underline{\text { Trecho da oficina }}$

- Aluno: Estou procurando no texto e não estou encontrando. Tom de frustração (Conversa afetiva).

- Aluno: No livro tem. São retirados do solo. (Conversa perceptiva).

- Professor: E onde são utilizados? 
- Aluno: Na indústria, nos carros, praticamente em todo lugar onde se queima alguma coisa para obter energia. (Estratégica de uso). Quando solicitados para relacionar a obtenção dos combustíveis e sua utilização usando o LD e TDC.

Já ao estabelecer a relação entre poluição atmosférica e a contribuição humana para este fenômeno, um dos alunos disse:

$\underline{\text { Trecho da oficina }}$

- Aluno: Como assim, que é relação entre poluição e como o homem contribui para sua geração? (Conversa afetiva).

- Professor: Exatamente. Como nós contribuímos para o aumento da poluição atmosférica?

- Aluno: A partir do uso dos motores movidos de combustão interna e o desmatamento. Com isso haverá o aumento de $\mathrm{CO}_{2}$, além de outros gases nocivos a vida em seu todo. (Conceitual complexa).

- Aluno: Motores de veículos, de fábricas, o fato de haver produção de bens de consumo potencializa o problema. (Conectiva com a vida).

- Aluno: (falando do Efeito estufa) A Terra está esquentado, devido a radiação do sol que parte dela passa pela camada de ozônio e outra parte é refletida para o espaço. Esta parte que atravessa a atmosfera é refletida no solo, voltando para a própria atmosfera. Os gases que formam a atmosfera esquentam, fazendo com que a Terra vire uma panela de pressão. (Conceitual complexa).

- Aluno: Do jeito que a mídia fala, parece que é tão ruim. Aqui no texto parece como algo natural, sempre existiu. É a nossa dependência de queima de combustível que fez ela ficar ruim.... (Conectiva com o conhecimento).

Apesar das limitações do estudo, isto é, com a participação voluntária de somente 18 alunos, os resultados parecem indicar que o uso articulado do LD+TDC contribuiu para o aumento de algumas categorias e a um maior equilíbrio entre elas, mostrando uma possível complementação dos diferentes textos.

Mesmo apresentando dificuldades por parte dos alunos em relação à leitura e a uma postura mais ativa, o professor, a partir do uso de textos, conseguiu estabelecer um ambiente de discussão. Ou seja, em todas as intervenções verificou-se a mediação do professor na condução dos diálogos, como pode ser notado na conversa abaixo: 
O professor ao estabelecer a relação entre poluição atmosférica e a contribuição humana para este fenômeno, trabalhado no TDC, o aluno precisou elaborar uma hipótese relacionada ao conceito trabalhado (Conceitual complexa): A relação é o desequilíbrio. Observou-se insegurança do aluno com receio de errar a resposta. O professor então interfere:

P: Você poderia explicar melhor este desequilíbrio? (Intervenção para identificar a ZDP)

Então o aluno respondeu, de maneira que seu envolvimento na atividade se sobressaiu aos demais: Então professor, desequilíbrio provocado pela humanidade e suas necessidades de bem-estar e consumo. Os seres vivos possuem a característica de eliminar $\mathrm{CO}_{2}$ em seu processo de respiração, nós estamos incluídos nisso, fazemos isso também. Mas somos os únicos com capacidade de mudar drasticamente o ambiente a nosso favor, exemplo disso a extração mineral como o carvão e o próprio petróleo. A poluição acontece quando, através da transformação daquilo que já foi produzido pelo ser humano e descartado é armazenado em demasia.

Verifica-se aqui a ação do professor na ZDP. De acordo com Carvalho (2013, p. 4), o papel do professor na construção do conhecimento é fundamental, sendo ele fomentador de questões para guiar o estudante e atuando na ZDP na direção de um desenvolvimento potencial.

Podemos perceber os altos níveis de concentração dos alunos ao formularem suas falas, demonstrando assim possíveis indícios de aprendizagem através da diminuição da ZDP articulada à mediação do professor articulada ao uso do TDC. O processo de internalização dos conceitos, por meio das generalizações expostas, nos leva a crer em níveis cognitivos elevados, possibilitando a formação de conceitos científicos. Isso vai de encontro com que Scarpa e Silva (2013) abordam, ou seja, para a formação de conceitos, a aprendizagem deve levar em conta aquilo que o aluno já sabe e, com ajuda de outro, estabelecer uma ZDP e através da mediação do professor ou outro estudante resolver algo que não conseguiria sozinho.

Em outro momento, pode-se ver a atuação do professor na formação de conceitos. Ao definir como a queima de combustíveis fósseis contribuem para o aquecimento global o professor interviu com uma explicação para direcionar o diálogo e descobrir a ZDP: O processo do aquecimento global é natural, assim como o efeito estufa. O problema é que quando o processo é natural os seres vivos se adaptam as modificações do ambiente relacionadas ao fenômeno. A questão é que o problema está sendo acelerado, promovendo um grande desequilíbrio ambiental. 
O Aluno demonstrou entender como aplicar o conhecimento adquirido no cotidiano: $E$ verdade, tanto no livro quanto no texto fala sobre isso. Se o processo é lento os seres vivos tem condições de se adaptar. Agora se não, provoca sérios problemas para a natureza e para os seres vivos. Corremos o risco de ficar sem comida e morrer de calor.

Em dado momento, no uso articulado do LD e do TDC, outro aluno pareceu estar intrigado em compreender a relação entre poluição atmosférica e a contribuição humana e perguntou: Como assim, o que é a relação entre poluição e o homem? E ele mesmo respondeu: é o homem que contribui para sua geração. Professor: Exatamente. E continuou: Como nós contribuímos para o aumento da poluição atmosférica?

Novamente podemos ver aqui o uso dos textos e a ação do professor na condução do diálogo e direcionamento do debate ao estabelecer a conexão entre as informações contidas no LD articulado ao TDC e o entendimento do aluno. Isso é corroborado por Rego (1994, p.115) quando afirma que "o professor assume uma posição de facilitador entre os alunos e o objeto do conhecimento, promovendo demonstrações, explicações, justificativas, abstrações e questionamentos" e também por Miceli e Rocha (2019), que mostram a importância do papel dos TDCs na geração de discussões e reflexões, com o professor mediando e auxiliando o processo. Podemos entender que ações executadas pelo professor podem viabilizar a consolidação das estruturas cognitivas do aluno. Desta maneira, recebe particular relevância considerar, de acordo com Vygotsky (2011), que a função primordial do professor é promover situações em que ocorra a mediação, planejando atividades e situações para que o aluno possa se apropriar do conhecimento, conferindo novos significados (MARTINS, 1997).

Pode-se então concluir, a partir dos resultados apresentados, que o uso articulado de TDC + LD e a atuação do professor conduziram os alunos na ressignificação de conceitos para o emprego deste conteúdo no cotidiano, unindo, de acordo com Almeida, Arnoni e Oliveira (2006), conhecimentos do cotidiano com os científicos. Desse modo, podemos supor que estas ações podem convergir ao que La Taille, Oliveira e Dantas (1992, p. 27) afirmam:

Se por um lado a ideia de mediação remete a processos de representação mental, por
outro lado refere-se ao fato de que os sistemas simbólicos que se interpõem entre o
sujeito de conhecimento têm origem social. Isto é, é a cultura que fornece ao indivíduo
os sistemas simbólicos de representação da realidade e, por meio deles, o universo de
significações que permite construir uma ordenação, uma representação, dos dados do
mundo real [...] O processo de internalização é assim, fundamental no
desenvolvimento do funcionamento psicológico humano...

Assim, os resultados mostram evidências que sugerem que o uso articulado do LD com o TDC (IT-3) conduz os alunos, com a ação mediadora do professor, a realizar maiores 
articulações dos conceitos trabalhados nos dois textos. Isso pode ser notado pela distribuição mais equilibradas das diferentes categorias de conversas quando comparado ao uso deles isoladamente (IT-1 e 2).

Neste presente estudo foi possível inferir que as potencialidades da articulação acontecem quando as linguagens adotadas na elaboração destes materiais (LD trata o assunto de maneira mais formal, o TDC trata do tema de maneira atualizada com uso de terminologias coloquiais, próxima do cotidiano do aluno) podem facilitar a mediação do professor, que pode associar diferentes maneiras de abordar um conhecimento, permitindo, então, ao aluno aprofundar conhecimentos e formar conceitos. Isso é corroborado por autores com Ferreira e Queiroz (2012) e Rosa e Goi (2020), ao afirmarem que ações, juntamente com leitura de TDC, podem desencadear maiores interações sociais entre os sujeitos e um pensamento crítico e reflexivo com articulação maior entre conceitos científicos e espontâneos, o que pode sugerir aprendizagem durante a interação. Ainda seguindo esses autores e também outros, o uso deste tipo de texto pode ser um recurso didático importante para a compreensão conceitos, além de procedimentos e atitudes, relacionando os conhecimentos científicos com o cotidiano e problemas reais (FERREIRA; QUEIROZ, 2012; PAGLIARINI; ALMEIDA, 2016).

\section{CONSIDERAÇÕES FINAIS}

$\mathrm{O}$ uso articulado do TDC com o LD permitiu ao professor mediar o processo ensino/aprendizagem de forma mais enriquecedora, motivando os alunos a uma maior participação nas atividades. O estudo demostrou, desta forma, que o uso de TDC atrelado ao uso do LD, com um complementando o outro, se mostrou mais eficiente, permitindo aos alunos fazerem relações cognitivas mais elevadas, evidenciado pela maior frequência de conversas em diferentes categorias, e contextualizar mais o conhecimento presente no LD, compreendendo melhor a ação do homem sobre o ciclo do carbono, contribuindo, assim, para que a aprendizagem fosse realmente significativa.

Mais estudos podem ser realizados no sentido de entender melhor o uso desse recurso (TDC) no ensino de ciências mais reflexivo e crítico, pois pode ser um fator importante na contextualização de conceitos e fenômenos científicos em sala de aula.

\section{REFERÊNCIAS}

ALLEN, Sue. Looking for Learning in Visitor Talk: A Methodological Exploration. In: LEINHARDT, Gaea; CROWLEY, Kevin; KNUTSON, Karen (Eds.). Learning

Conversations in Museums. Nova Jersey: LEA Publishers, 2002. 
ALMEIDA, José Luís Viera de; ARNONI, Maria Eliza Brefere.; OLIVEIRA, Edson Moreira de. Mediação Pedagógica: Dos limites da lógica formal à necessidade da lógica dialética no processo ensino-aprendizagem. Anais da 29a Reunião Anual Anped, São Paulo, 2006.

BESSA, Eduardo; FRANÇA, Cecília; ARNT, Ana de Medeiros. Divulgação Científica para professores. Tangará da Serra: Ideias, 2015.

CACHAPUZ, Antonio. A Necessária renovação do ensino das ciências. São Paulo: Cortez, 2005.

CARVALHO, Ana Maria Pessoa de. Os Estágios nos Cursos de Licenciatura. São Paulo: Cengage Learning, 2012.

CARVALHO, Ana Maria Pessoa de. O ensino de Ciências e a proposição de sequências de ensino investigativas. In: CARVALHO, Ana Maria Pessoa de (Org.), Ensino de Ciências por Investigação: condições para sua implementação em sala de aula. São Paulo: Cengage Learning, 2013.

CHAVES, Taniamara Vizzotto; MACHADO, Rodrigo Batista. Uma proposta para o ensino de física com textos de divulgação científica. Atas do XVI Simpósio nacional de ensino de física, 2005. Disponível em

http://www.cienciamao.usp.br/dados/snef/_espacocienciadocolegiosa_1.trabalho.pdf Acesso em 04 maio 2017.

COLAÇO, Veriana de Fátima Rodrigues; PEREIRA, Eleonora; NETO, Francisco Edmar Pereira; CHAVES, Hamilton Viana; SÁ, Ticiana Santiago de. Estratégia de mediação em situação de interação entre crianças em sala de aula. Estudos de Psicologia, v. 12, n.1, p. 4,756, 2007. http://dx.doi.org/10.1590/S1413-294X2007000100006. Acesso em 10 mar. 2016

DELIZOICOV, Demétrio; ANGOTTI, José André; PERNAMBUCO, Marta Maria. Ensino de Ciências: fundamentos e métodos. São Paulo: Cortez, 3 ed., 2009.

FERREIRA, Luciana Nobre de Abreu; QUEIROZ, Salete Linhares. Textos de Divulgação Científica no Ensino de Ciências: uma revisão. Alexandria, v. 5, n. 1, p. 3-31, 2012.

Disponível em https://periodicos.ufsc.br/index.php/alexandria/article/view/37695 Acesso em 03 mar. 2016.

FREITAS, M. T. A. Vygotsky e Bakhtin - Psicologia e educação: Um intertexto. São Paulo: Ática, 4ed, 2000.

FREITAS, Olga. Equipamentos e materiais didáticos. Brasília: Universidade de Brasília, 2009. Disponível em http://portal.mec.gov.br/index.php?option=com_docman\&view=download\&alias=614equipamentos-e-materiais-didaticos\&Itemid=30192. Acesso em: 28 mar. 2016.

GIL, Antônio Carlos. Pesquisa social. São Paulo: Atlas, 1999.

La TAILlE, Yves de; OLIVEIRA, Marta Kohl; DANTAS, Heloysa. Piaget, Vygotsky, Wallon: teorias psicogenéticas em discussão. São Paulo: Summus editorial, 1992. 
LOIOLA, Lidiane; ZANCUL, Mariana de Senzi; BIZERRIL, Marcelo. Uso de textos de divulgação cientifica no desenvolvimento de temas de Educação em Saúde na Educação de Jovens e Adultos (EJA). Atas do IX Encontro Nacional de Pesquisa em Educação Ciências - IX ENPEC, 2013. Disponível em http://abrapecnet.org.br/atas_enpec/ixenpec/atas/resumos/R0576-1.pdf Acesso em 10 set. 2016.

LOUREIRO, Carlos Frederico B. Educar, participar e transformar em educação ambiental. Revista Brasileira de Educação Ambiental, v. 0, p. 13-20, 2004. Disponível em http://assets.wwfbr.panda.org/downloads/revbea_n_zero.pdf\#page=13 Acesso em 22 jan. 2017.

LÜDKE, Menga; ANDRÉ, Marli Eliza Dalmazo Afonso de. Pesquisa em Educação: Abordagens Qualitativas. Ed. EPU, 2 ed.: Rio de Janeiro, 2014

MARTINS, José Carlos. Vygotsky e o Papel das Interações Sociais na Sala de Aula: Reconhecer e Desvendar o Mundo. Série Idéias. n. 28, p. 111-122. São Paulo: FDE, 1997. Disponível em http://www.crmariocovas.sp.gov.br/pdf/ideias_28_p111-122_c.pdf Acesso em 20 mar 2016.

MARTINS, Isabel: NASCIMENTO, Tatiana Galieta; ABREU, Teo Bueno de. Clonagem na sala de aula: um exemplo do uso didático de um texto de divulgação. Investigações em Ensino de Ciências, v. 9, n. 1, p. 95-111, 2004. Disponível em https://www.if.ufrgs.br/cref/ojs/index.php/ienci/article/view/536 Acesso em 3 fev. 2018.

MICELIA, Bruna Sarpa; ROCHA, Marcelo Rocha. Análise de Textos de Divulgação Científica sobre Genética Inseridos em Livros Didáticos de Biologia. Alexandria, v. 12, n. 2, p. 121-138, 2019. http://dx.doi.org/10.5007/1982-5153.2019v12n2p121 Acesso em 30 ago. 2020.

PAGLIARINI, Cassiano Rezende; ALMEIDA, Maria José P. M de. Leituras por alunos do ensino médio de textos de cientistas sobre o início da física quântica. Ciência e Educação, v. 22, n.2, p. 299-317, 2016. https://doi.org/10.1590/1516-731320160020003. Acesso em 3 abr. 2018.

PILETTI, Nelson. Psicologia da aprendizagem: da teoria do condicionamento ao construtivismo. São Paulo: Contexto, 2015.

REGO, Teresa Cristina. Vygotsky: uma perspectiva histórico-cultural da educação. Petrópolis: Vozes, 1994.

ROCHA, Marcelo Borges. Textos de divulgação científica na sala de aula: a visão do professor de ciências. Revista Augustus, v. 14, n. 29, p. 24-34, 2010. Disponível em http://apl.unisuam.edu.br/augustus/pdf/ed29/rev_augustus_ed29_02.pdf

ROCHA, Marcelo Borges. O potencial didático dos textos de divulgação científica segundo professores de ciências. Revista Brasileira de Ensino de Ciência e Tecnologia, v. 5, n.2, p. 47-68, 2012. Doi: 10.3895/S1982-873X2012000200005. Acesso em 10 out. 2017. 
ROSA, Ana Paulo; GOI, Mara Elisângela Jappe. A utilização de textos de divulgação científica no ensino de Química. Research, Society and Development, v. 9, n. 6, e123963480, 2020. http://dx.doi.org/10.33448/rsd-v9i6.3480 Acesso em 28 ago. 2020.

SCARPA, Daniela Lopes; SILVA, Maíra Batistoni. A Biologia e o ensino de Ciências por investigação: dificuldades e possibilidades. In: CARVALHO, Ana Maria Pessoa de (Org.), Ensino de Ciências por Investigação: condições para implementação em sala de aula.São Paulo: Cengage Learning, 2013.

SILVEIRA, Mariana Leite da; ARAUJO, Magnólia Fernandes Florêncio de. O papel do livro didático de biologia na opinião de professores em formação: implicações sobre a escolha e avaliação. Revista da SBEnBIO, v. 7, p. 5594-5605, 2014.

VAN DER VIER, Rene; VALSINER, Jaan. Uma Síntese. São Paulo: Loyola, 7 ed., 2006.

VYGOTSKY, Lev Semenovitch. (2013). A formação social da mente. São Paulo: Ed. Martins Fontes, 2013.

VYGOTSKY, Lev Semenovitch. Pensamento e linguagem. São Paulo: Ed. Martins Fontes, 2011.

Recebido em: 8 de maio de 2020.

Aprovado em: 31de agosto de 2020. 